\title{
Influence of erythromycin on establishment of feeding in preterm infants: observations from a randomised controlled trial
}

\author{
Ben J Stenson, Linda Middlemist, Andrew J Lyon
}

\begin{abstract}
Aim-To determine the effect of erythromycin on the establishment of enteral feeding in ventilated infants $<31$ weeks gestation.

Methods-Erythromycin was randomly allocated as an antimicrobial treatment for the first 7 days of life in 76 infants: 35 received erythromycin and 41 acted as controls. Feed toleration, time taken to establish full enteral feeding, vomiting, prescription of glycerine suppositories and occurrence of necrotising enterocolitis were recorded.

Results-There were no significant differences between the groups for any of the outcomes. The infants treated with erythromycin reached full feeding at a median (quartile) age of 8 (5-12) days compared with 9 (6-14) days for controls.

Conclusions-Intravenous erythromycin in antimicrobial doses is unlikely to benefit the introduction of feeding in preterm infants.
\end{abstract}

(Arch Dis Child Fetal Neonatal Ed 1998;79:F212-F214)

Keywords: erythromycin; motility; motilin

The antibiotic erythromycin is a potent analogue of the gastrointestinal hormone motilin. ${ }^{1}$ This hormone stimulates gastric emptying and induces phase 3 migrating motor complexes in the proximal intestine which are thought to be responsible for the transit of luminal contents through the gut. ${ }^{2}$ Erythromycin has been used successfully as a prokinetic agent in young infants with intestinal dysmotility, ${ }^{34}$ but its role in preterm infants is less clear. The migrating motor complex is immature before 32 weeks of gestation. ${ }^{5}{ }^{6}$ Infants $<30$ weeks gestation have shown increased gastric motility after erythromycin infusion but not increased duodenal motility. ${ }^{7}$ Intragastric erythromycin induced migrating motor activity in infants beyond 32 weeks of gestation but not in less mature infants. ${ }^{8}$ Preterm infants usually take several days to tolerate full enteral feeding and are at high risk of feeding related complications such as necrotising enterocolitis. There are no data evaluating the effects of erythromycin on feed toleration in preterm infants.

Chronic lung disease continues to be a common problem among the survivors of preterm birth. It has been postulated that infection with Ureaplasma urealyticum is associated with the development of chronic lung disease and this has been studied in a prospective randomised trial using erythromycin given from birth in ventilated preterm infants. ${ }^{9}$ We hypothesised that the infants receiving erythromycin in the trial would to tolerate enteral feeds better and progress more rapidly to full milk feeding than the control infants.

\section{Methods}

Infants $<31$ weeks gestation that were ventilated on day 1 of life and free of congenital abnormality were eligible for inclusion in the study. Written parental consent was obtained before randomisation. The study was approved by the institutional ethics committee.

Enrolled infants were randomly allocated to receive either intravenous erythromycin infusion $15 \mathrm{mg} / \mathrm{kg}$ three times daily for the first 7 days in addition to their standard treatment or no additional treatment. After each infant's discharge from the unit, the nursing and medical records were examined and the age at which milk was first offered and the time taken to reach full enteral feeding were recorded. Feed toleration was assessed as the net enteral balance (nasogastric feed volume minus volume of nasogastric aspirate) on each of the first 14 days of life. The type of milk used, the number of infants that vomited, and the number prescribed glycerine suppositories because of concerns about delayed passage of meconium during the study period were recorded. Necrotising enterocolitis was diagnosed in the presence of radiographic pneumatosis intestinalis or confirmatory operative findings. The staff responsible for feeding the infants were not aware that feeding patterns would later be studied. According to standard nursery policy, feeds were given hourly $(1 \mathrm{ml})$ by nasogastric tube as soon as the infants were stable and not receiving neuromuscular blocking agents. The feeds were then increased as tolerated in increments of $1 \mathrm{ml}$ until full feeding was achieved.

Full enteral feeding was defined as the point when all calorie intake and fluids were being given as enteral milk (usually $150 \mathrm{ml} / \mathrm{kg}$ body weight per day of enteral milk or more). Every effort was made to obtain expressed maternal breast milk as the initial feed. Donor breast milk was not used. No other gastrointestinal prokinetic agents were used. Parenteral nutrition was used until full feeding was established.

Differences between continuous variables were analysed using the Mann Whitney-U test. Distributions of categorical variables were analysed using the $\chi^{2}$ test. Differences between groups were regarded as significant at $\mathrm{p}<0.05$. 
Table 1 Patient characteristics: data are median (range) or number (\%)

\begin{tabular}{llll}
\hline & Erythromicin $(n=35)$ & Controls $(n=41)$ & $p$ Value \\
\hline Gestation (weeks) & $28(24-30)$ & $29(23-30)$ & $\mathrm{p}=0.586$ \\
Birthweight (g) & $1025(590-2300)$ & $1050(500-1670)$ & $\mathrm{p}=0.934$ \\
IUGR (<10th centile) & $3(9)$ & $3(7)$ & $\mathrm{p}=0.822$ \\
Gender (male/female) & $18 / 17$ & $30 / 11$ & $\mathrm{p}=0.050$ \\
Milk (breastformula) & $27 / 5$ & $31 / 5$ & $\mathrm{p}=0.840$ \\
Antenatal steroids & $22(63)$ & $32(78)$ & $\mathrm{p}=0.146$ \\
Morphine & $23(66)$ & $24(59)$ & $\mathrm{p}=0.521$ \\
Pancuronium & $10(29)$ & $11(27)$ & $\mathrm{p}=0.866$ \\
\hline
\end{tabular}

Table 2 Outcomes: data are median (quartile) or number (\%)

\begin{tabular}{llll}
\hline & Erythromycin $(n=35)$ & Controls $(n=41)$ & $p$ Value \\
\hline Age feeds offered (days) & $3(2-4)$ & $3(2-5)$ & $\mathrm{p}=0.338$ \\
Age full feeds (days) & $8(5-12)$ & $9(6-14)$ & $\mathrm{p}=0.450$ \\
Glycerine suppositories & $15(43)$ & $24(58)$ & $\mathrm{p}=0.173$ \\
Vomited & $12(34)$ & $10(24)$ & $\mathrm{p}=0.590$ \\
Necrotising enterocolitis & $2(6)$ & $4(10)$ & $\mathrm{p}=0.413$ \\
Died & $7(20)$ & $8(20)$ & $\mathrm{p}=0.917$ \\
\hline
\end{tabular}

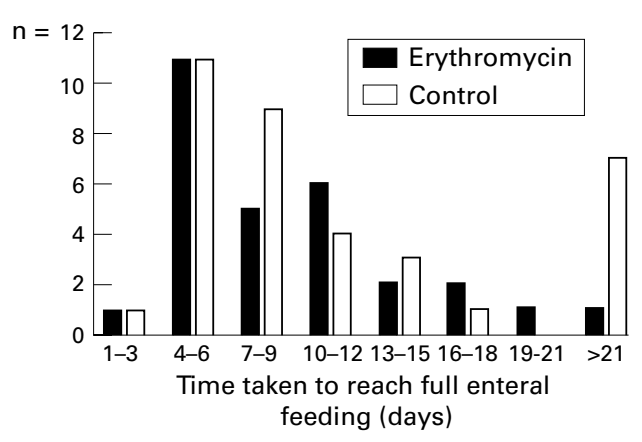

Figure 1 Frequency distribution for time taken to reach full enteral feeding (days).

\section{Results}

Seventy six infants were enrolled in the study. Their characteristics at study entry are given in table 1 . There was no significant difference between the two groups in terms of birthweight, gestational age, or the number of infants in each group that received antenatal steroids, or postnatal morphine or pancuronium. There was a higher proportion of boys in the control group $(\mathrm{p}=0.05)$.

The feed toleration of the two groups is detailed in table 2 . There was no significant difference between the two groups in age at which feeds were first offered or in time taken to full enteral feeding. The number of infants who vomited, received glycerine suppositories, developed NEC or died was not significantly different between the two groups. Fig 1 shows

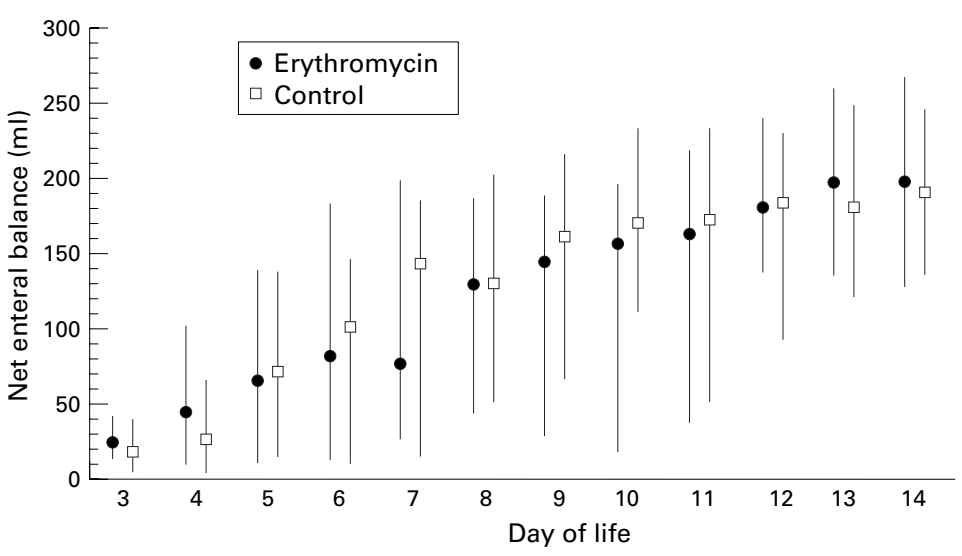

Figure 2 Net enteral milk balance on days 3 to 14: data are median (quartiles). the frequency distribution of time taken in days to reach full enteral feeding for the two groups. Median net enteral balance during days 3 to 14 is shown in fig 2 . There was no significant difference between the two groups at any point during this period.

The first milk offered was expressed breast milk in $85 \%$ of cases, with no significant difference between the groups in this respect. The use of expressed breast milk did not delay the onset of feeding. The median age at onset of feeding was day 3 for both formula fed and breast fed infants. The median age at full feeds was nine days for both feed types. All of the infants that developed confirmed necrotising enterocolitis had been fed with expressed breast milk. Their feeds were started at a median 4 days of age. Antenatal steroids had been received by $71 \%$ of the infants including four of the six that developed necrotising enterocolitis. Neither age at onset of feeding nor time to full feeds was influenced by exposure to antenatal steroids.

\section{Discussion}

This study has not shown any clinically significant beneficial effect for erythromycin infusion on the feed toleration of ventilated preterm infants less than 31 weeks gestation. A small benefit has not been excluded. The sample size for the study was calculated to be adequate for the primary outcomes of the study which were measures of lung injury and inflammation. Although none of the differences was significant, the infants treated with erythromycin reached full enteral feeding one day sooner, were prescribed fewer glycerine suppositories, and developed less necrotising enterocolitis. A sample size of 100 infants per group would be required to have $80 \%$ power to show a difference in the mean time to full feeds of two days at the $5 \%$ level of significance. A substantially larger study would be required to determine any possible effect on necrotising enterocolitis.

Manometric measures of gut motility have shown that erythromycin infusion increases gastric antral contractions but does not induce small intestinal phase 3 activity in infants $<30$ weeks gestation, ${ }^{7}$ while in more mature infants it does stimulate phase 3 activity. ${ }^{3}$ Similar findings have been documented with intragastric erythromycin. ${ }^{8}$ Despite their lack of phase 3 activity, infants $<30$ weeks gestation generally establish feeding so phase 3 activity is not an absolute prerequisite for successful feeding.

The erythromycin was given at an antimicrobial dose of $15 \mathrm{mg} / \mathrm{kg}$. A dose of $12 \mathrm{mg} / \mathrm{kg}$ was effective in treating postoperative intestinal dysmotility in infants, ${ }^{3}$ although studies in dogs suggest that a smaller dose may be more effective. ${ }^{10}$ Treatment allocation was not blinded as it was felt to be unacceptable to insert intravenous cannulae into infants at risk of intraventricular haemorrhage solely for the purpose of administering a placebo. Because the erythromycin was administered as a one hour infusion, dedicated vascular access was required. The nursery staff who fed the infants did not know that feeding outcomes would be 
studied later and the data gathered were objective measurements recorded in the case records which were not liable to measurement bias by the study personnel. The feeding regimen used reflected the standard nursery practice of caution against rapid increases in feeds because of the high risk of the population for necrotising enterocolitis. Both groups tolerated their feeds well at this rate of increase. If feeds had been introduced more rapidly a difference between the two groups might have been more readily identified. If a subpopulation of preterm infants with established feeding difficulty had been studied different results might have been obtained. Nevertheless, as fig 1 shows, the feeding policy permitted a wide variation between infants in the time taken to reach full feeding.

Although the background figure for breast feeding in healthy term infants on day 7 of life in our institution is around $50 \%,{ }^{11}$ with encouragement, it was possible to obtain expressed breast milk for $85 \%$ of these preterm infants. Breast milk leaves the stomach more rapidly than formula milk, ${ }^{12}$ although this is probably not through any direct action on gut motility. ${ }^{13}$ There was no significant difference in feed toleration attributable to the type of milk used in this study.

In conclusion, the use of erythromycin as an antimicrobial agent in ventilated infants less than 31 weeks gestation is unlikely to have important beneficial effects on the introduction of enteral feeding. This may be because gut motility is immature at this time. Further studies of preterm infants with established intestinal dysmotility will be required to determine whether it has any role as a prokinetic agent in this age group.

1 Peeters T, Matthijs G, Depoortere I, Cachet T, Hoogmartens J, Vantrappen G. Erythromycin is a motilin receptor agonist. Am F Physiol 1989;257:G470-G4.

2 Kerlin P, Zinsmeister A, Philips S. Relationship of motility to flow of contents in the human small intestine, Gastroenterology 1982;82:701-6.

3 Simkiss DE, Adams IP, Myrdal U, Booth IW. Erythromycin in neonatal postoperative intestinal dysmotility. Arch Dis in neonatal postoperative

$4 \mathrm{Ng}$ PC, Fok TF, Lee CH, Wong W, Cheung KL Erythromycin treatment for gastrointestinal dysmotility in prythromycin treatment for gastrointestinal dysmotility

preterm infants. F Pediatr Child Health 1997;33:148-50.
5 Bisset WM, Watt JB, Rivers RPA, Milla PJ. Ontogeny of fasting small intestinal motor activity in the human infant. Gut 1988;29:483-8.

6 Berseth CL. Gestational evolution of small intestinal motility in preterm and term infants. $\mathcal{F}$ Pediatr 1989;115:64651.

7 Tomomasa T, Miyazaki M, Koizumi T, Kuroume T. Erythromycin increases gastric antral motility in human premature infants. Biol Neonate 1993;63:349-52.

8 Jadcherla SR, Klee G, Berseth CL. Regulation of migrating motor complexes by motilin and pancreatic polypeptide in human infants. Pediatr Res 1997;42:365-9.

9 Lyon AJ, McColm J, Middlemist L, Fergusson S, McIntosh N, Ross PW. Randomised trial of erythromycin on the development of chronic lung disease in preterm infants. development of chronic lung dis

10 Otterson MF, Sarna SK. Gastrointestinal motor effects of erythromycin. Am f Physiol 1990;259:G355-G63.

11 Ferguson AE, Tappin DM, Girdwood RWA, Kennedy R, Cockburn F. Breast feeding in Scotland. $B M \mathcal{F}$ 1994;308:824-5.

12 Cavell B. Gastric emptying in infants fed human milk or infant formula. Acta Paediatr Scand 1981;70:639-41.

13 Tomomasa T, Hyman PE, Itoh K, et al. Gastroduodenal motility in neonates: response to human milk compared with cow's milk formula. Pediatrics 1987;80:434-8. 